\title{
Cytoprotective role of autophagy during paclitaxel-induced apoptosis in Saos-2 osteosarcoma cells
}

\author{
HYEON JUN KIM ${ }^{2}$, SEUNG GEE LEE ${ }^{1,4}$, YOON-JAE KIM ${ }^{1,4}$, JI-EUN PARK ${ }^{1,3}$, \\ KYU YEOL LEE ${ }^{2}$, YOUNG HYUN YOO ${ }^{1,3,4}$ and JONG-MIN KIM ${ }^{1,3,4}$
}

\author{
Departments of ${ }^{1}$ Anatomy and Cell Biology and ${ }^{2}$ Orthopaedic Surgery, College of Medicine, \\ ${ }^{3}$ Medical Research Science Center and ${ }^{4}$ Mitochondria Hub Regulation Center, \\ Dong-A University, Busan 602-714, Republic of Korea
}

Received January 14, 2013; Accepted March 11, 2013

DOI: 10.3892/ijo.2013.1884

\begin{abstract}
Osteosarcoma (OS) is the most common primary malignant bone cancer in children and adolescents. Although paclitaxel (PCX) has been considered one of the most important cancer chemotherapeutic drugs, the current protocols for OS treatment do not incorporate this agent. Therefore, the purpose of this study was to evaluate the induction of cell death in OS cells after exposure to PCX, to identify the cell death mechanism(s) activated by PCX and to investigate whether autophagy is associated with PCX-induced apoptosis. The results of the present study confirmed that exposure to low PCX concentrations can induce apoptotic cell death in Saos-2 cells; furthermore, caspase-3 activation, PARP degradation and XIAP downregulation were observed in combination with PCX-induced apoptosis. The potential involvement of mitochondrial events (intrinsic apoptotic pathway) in PCX-induced apoptosis in OS cells was verified by the alteration (depolarization) of mitochondrial membrane potential. In addition, pretreatment with 3-methyladenine (3-MA), a specific inhibitor of autophagy, significantly increased PCX-induced apoptotic cell death in Saos-2 cells. The augmentation of PCX-induced apoptosis by 3-MA was accompanied by increase in the cytochrome $c$ release from the mitochondria, caspase- 3 activity and XIAP downregulation, which suggests that inhibiting autophagy further stimulates the PCX-induced mitochondrionrelated (intrinsic) apoptotic pathway by provoking caspase-3 activation. Thus, autophagy observed during PCX-induced apoptosis in Saos-2 OS cells represents the role of cytoprotection in cellular homeostatic processes. In conclusion, the results of this study revealed that PCX exposure effectively induces OS cell death by apoptosis associated with the mitochondrial-mediated caspase-dependent pathway. PCX
\end{abstract}

Correspondence to: Dr Jong-Min Kim, Department of Anatomy and Cell Biology, College of Medicine, Dong-A University, Dongdaeshin-dong 3-1, Seo-gu, Busan 602-714, Republic of Korea E-mail: jmkim7@dau.ac.kr

Key words: paclitaxel, autophagy, caspase, cytochrome c, apoptosis, osteosarcoma cells can increase autophagic activity and suppressing autophagy enhances PCX-induced apoptosis in OS cells. Therefore, it is suggested that combination treatment involving low-dose PCX therapy and autophagy inhibitor therapy could be an effective and potent strategy for improved chemotherapy for OS in the near future.

\section{Introduction}

Osteosarcoma (OS) is the most common primary malignant bone cancer in children and adolescents and is typically observed in individuals between the ages of 10 and 25 years (average age, 18 years) (1). In most cases, OS originates from the metaphysis of long bones and is mostly found in areas of rapid growth in children, i.e., the knees and shoulders and the long bones of the arms and legs (2). OS is highly aggressive and primarily metastasizes to the lungs (3). The 10-year disease-free survival rate is $\sim 60$ and $30 \%$ in patients with localized disease and patients with metastasis at diagnosis, respectively, with the current use of adjuvant and neoadjuvant chemotherapy involving doxorubicin, methotrexate, cisplatin and vincristine $(4,5)$. Therefore, new therapeutic strategies need to be evaluated to improve OS survival, especially for patients refractory to current chemotherapy regimens.

Various chemotherapeutic drugs are reported to induce apoptosis in OS cells (6-8). Two apoptotic pathways have been proposed: one pathway involves cell death receptors (TNF-R or Fas) in the cell membrane, where binding of ligands to the receptors activates the caspase- 8 and, in turn, activates downstream effector caspases (caspase-3 and -7) (9). The other pathway is associated with mitochondrial alterations such as decrease in mitochondrial membrane potential and release of cytochrome $\mathrm{c}$ from the mitochondrial membrane, followed by activation of effector caspases via the activation of caspase- 9 (10). In both pathways, the activation of effector caspases is known to be suppressed by X-linked inhibitor-of-apoptosis protein (XIAP) (11). During the apoptotic process, the apoptotic mechanism can be classified as a caspase-dependent or caspase-independent pathway, depending on the involvement of caspase activation (12). The release of apoptosis-inducing factor (AIF) from the mitochondrial membrane is believed to be a specific marker for the caspase-independent pathway (13). 
AIF contains a nuclear localization signal and translocates to the nucleus where it participates in chromatin condensation and large-scale DNA fragmentation (13).

During the last decade, autophagy has been gradually recognized by another type of cell death machinery in several cellular systems $(14,15)$. Autophagy is a cellular process whose primary function is to degrade long-lived proteins and recycle cellular components (16). Autophagy can be induced by various stimuli, including starvation (17), cytokines (18), caspase inhibition (19) and chemical reagents such as rapamycin (20). In mammalian cells, autophagy has been implicated in cellular processes as varied as cell survival (17), death $(19,20)$, pathogen clearance (18) and antigen presentation (21) and has also been associated with pathological processes such as cancer progression and neurodegenerative diseases $(22,23)$.

Paclitaxel (Taxol ${ }^{\circledR}$ ), a polyoxygenated naturally occurring diterpenoid isolated from the bark of the Pacific yew tree (Taxus brevifolia), has been considered one of the most important cancer chemotherapeutic drugs (24). PCX has a potent ability to stabilize microtubules. The anticancer activity of this drug is ascribed to its unique mechanism of action, i.e. causing mitotic arrest in cancer cells, which leads to apoptosis through inhibition of microtubule depolymerization (25). However, the current protocols for OS treatment do not incorporate this agent (26). The purpose of this study was to evaluate the induction of cell death in OS cells after exposure to PCX, to identify the cell death mechanism(s) activated by PCX and to investigate whether autophagy is associated with PCX-induced apoptosis.

\section{Materials and methods}

Reagents and antibodies. Paclitaxel (PCX) was obtained from Bristol-Myers Squibb (New York, NY, USA). 3-methyladenine (3-MA), 3-(4,5-dimethylthiazol-2-yl)-2,5-diphenyltetrazolium bromide (MTT), propidium iodide (PI) and Rhodamine 123 and anti-actin antibody were obtained from Sigma-Aldrich (St. Louis, MO, USA). Antibody for microtubule associated protein 1 light chain 3 (LC3) was purchased from Novus Biologicals (Littleton, CO, USA). Antibodies for cytochrome c, Hsp60, XIAP and PARP were obtained from Santa Cruz Biotech (Santa Cruz, CA, USA). Active-form specific antibody for caspase-3 was from Cell Signaling Tech (Beverly, MA, USA). Rabbit and mouse IgG-conjugated with horseradish peroxidase were from Amersham Pharmacia Biotech (Piscataway, NJ, USA).

Cell culture and drug treatment. Saos-2 cells (human osteosarcoma cell line; American Type Culture Collection, Rockville, MD, USA) were cultured in Dulbecco's modified Eagle's medium (DMEM) nutrient mixture F-12 HAM (Sigma, St. Louis, MO, USA) containing 10\% fetal bovine serum (Invitrogen, Carlsbad, CA, USA) and $1.2 \mathrm{~g} / 1$ sodium bicarbonate supplemented with $10 \mu \mathrm{g} / \mathrm{ml}$ penicillin-streptomycin (Invitrogen). The cells were incubated in a humidified incubator at $37^{\circ} \mathrm{C}$ with $5 \% \mathrm{CO}_{2}$ and were exposed to PCX or 3-MC when the confluency reached $30 \%$.

MTT cell viability assay. Cells were seeded in 12-well plates at a density of $5 \times 10^{5}$ cells per well. After treatment at an appro- priate time $(48,72$, or $96 \mathrm{~h})$, the culture medium was removed and replaced with a medium containing $0.5 \mathrm{mg}$ of MTT dissolved in PBS ( $\mathrm{pH} 7.2$ ); after $4 \mathrm{~h}$, the formed crystals were dissolved with dissolved with $200 \mathrm{ml}$ of DMSO. The intensity of the color in each well was measured at a wavelength of $490 \mathrm{~nm}$ using a microplate reader (BioTek EL-312e, VT, USA).

Cell cycle analysis. The cells were harvested, fixed with $95 \%$ ethanol for $24 \mathrm{~h}$, incubated with $0.05 \mathrm{mg} / \mathrm{ml}$ PI and $1 \mu \mathrm{g} / \mathrm{ml}$ RNase A at $37^{\circ} \mathrm{C}$ for $30 \mathrm{~min}$ and analyzed by flow cytometry, using an Epics XL and analysis software (EXPO32 ${ }^{\mathrm{TM}}$; Beckman Coulter, MI, USA). The cells belonging to the sub-G1 population were considered to be apoptotic cells; the percentage of each phase of the cell cycle was determined.

Annexin $V$ cell death assay. The cells were stained using the AnnexinV-FITC Apoptosis Detection kit (BD Biosciences, NJ, USA) according to the manufacturer's protocol. Stained cells were analyzed by flow cytometry.

Western blot analysis. Whole-cell lysates were prepared by incubating cell pellets in lysis buffer [ $30 \mathrm{mM} \mathrm{NaCl}, 0.5 \%$ Triton $\mathrm{X}-100,50 \mathrm{mM}$ Tris- $\mathrm{HCl}$ (pH 7.4), $1 \mathrm{mM} \mathrm{Na} \mathrm{VO}_{4}, 25 \mathrm{mM} \mathrm{NaF}$, $10 \mathrm{mM} \mathrm{Na} \mathrm{P}_{2} \mathrm{O}_{7}$ ] for $30 \mathrm{~min}$ on ice. After the insoluble fractions were removed by centrifugation at $14,000 \mathrm{rpm}$ at $4^{\circ} \mathrm{C}$ for $30 \mathrm{~min}$, the supernatants were collected and protein concentration was determined with a BCA protein assay kit (Pierce Biotechnology, Woburn, MA, USA). The same amounts of proteins $(\sim 30 \mu \mathrm{g})$ were subjected to SDS-PAGE and transferred onto a nitrocellulose membrane. The membranes were incubated for $1 \mathrm{~h}$ at room temperature (RT) with a primary antibody in Tris-buffered saline containing $0.05 \%$ Tween-20 [TBS-T ( $\mathrm{pH} 7.4)]$ in the presence of 5\% non-fat dry milk. After the membranes were washed in TBS-T, secondary antibody reactions were performed with an appropriate source of antibody conjugated with horseradish peroxidase. The signals were detected with an enhanced chemiluminescence detection kit (Amersham Pharmacia Biotech) in the LAS-3000 detector (Fujifilm, Japan). Immunoblotting for $\beta$-actin was performed in each experiment as an internal control.

Preparation of mitochondrial fractions. The cells $\left(5 \times 10^{7}\right)$ were washed in TD buffer ( $135 \mathrm{mM} \mathrm{NaCl}, 5 \mathrm{mM} \mathrm{KCl}, 25 \mathrm{mM}$ Tris- $\mathrm{Cl}$, $\mathrm{pH}$ 7.6) and allowed to swell for $15 \mathrm{~min}$ in ice-cold hypotonic CaRSB buffer $\left[10 \mathrm{mM} \mathrm{NaCl}, 1.5 \mathrm{mM} \mathrm{CaCl}_{2}, 10 \mathrm{mM}\right.$ Tris- $\mathrm{Cl}$ (pH 7.5) protease inhibitors]. Cells were Dounce-homogenized with 30 strokes and mitochondria stabilization buffer $(210 \mathrm{mM}$ mannitol, $70 \mathrm{mM}$ sucrose, $5 \mathrm{mM}$ EDTA, $5 \mathrm{mM}$ Tris, $\mathrm{pH}$ 7.6) was added. After removing nuclear contaminants $(690 \mathrm{x} \mathrm{g}$ for $15 \mathrm{~min}$ ), the supernatant was centrifuged at $20,800 \times \mathrm{g}$ for 15 min. Finally, the pellet (mitochondria) was directly diluted with lysis buffer [5 M NaCl, $1 \mathrm{M}$ Tris- $\mathrm{Cl}$ (pH 7.6), 5\% Triton $\mathrm{X}-100$, protease inhibitors] and the mitochondria (pellet) and supernatant (cytosol) were applied for protein analysis.

Caspase-3 activity assay. A fluorometric assay kit (Clontech, CA, USA), which contains fluorogenic substrate specific for caspase-3 immobilized in the wells, was used to evaluate enzyme activity. Ten micrograms of the extracted proteins in homogenization buffer $(50 \mathrm{mM}$ Tris- $\mathrm{HCl}, 150 \mathrm{mM} \mathrm{NaCl}$, 
$10 \%$ glycerin and $1 \%$ Triton $\mathrm{X}-100)$ were added to the wells. The plate was incubated in the fluorescence plate reader at $37^{\circ} \mathrm{C}$ for $3 \mathrm{~h}$ and fluorescence was read every $10 \mathrm{~min}$. The activity was determined by fluorometric detection (excitation, $380 \mathrm{~nm}$; emission, $460 \mathrm{~nm}$ ) and the negative control (blank, without sample) was subtracted from all the samples. Results at $2 \mathrm{~h}$ were selected, as the manufacturer suggested. Baseline values of negative controls and samples with specific inhibitors did not increase during the 2-h interval.

Measurement of mitochondrial membrane potential (MMP). The cells $\left(5 \times 10^{5}\right)$ were incubated with $1 \mu \mathrm{M} \mathrm{JC}-1$ dye at $37^{\circ} \mathrm{C}$ for $15 \mathrm{~min}$, washed and resuspended with PBS and then the fluorescence [red $(585 / 590 \mathrm{~nm})$; green $(510 / 527 \mathrm{~nm})$ ] was measured by flow cytometer.

Immunocytochemistry. Harvested cells were attached on the slide glass by cytospin centrifugation. The cells were fixed with 4\% PFA, washed with PBS and incubated with $0.2 \%$ Triton $\mathrm{X}-100$. Then, the cells were incubated with the appropriate primary antibody in $1 \%$ bovine serum albumin at RT. For secondary antibody reaction, the cells were incubated with an appropriate fluorescence-conjugated secondary antibody at RT. For counterstaining of the nucleus, if required, cells were incubated with PI $(50 \mu \mathrm{g} / \mathrm{ml})$ at RT. Finally, cells were mounted and observed under a confocal microscope (LSM510, Carl Zeiss, Germany).

Statistical analyses. Data were expressed as the mean \pm SD of three or four separate experiments. Where appropriate, data were subjected analysis of variance (ANOVA) followed by Duncan's post hoc test. Means were considered significantly different at $\mathrm{p}<0.05$.

\section{Results}

PCX can induce cell death in osteosarcoma Saos-2 cells. To investigate whether PCX has a cytotoxic effect on osteosarcoma Saos-2 cells, the cells were exposed to various concentrations of PCX (2.5-100 nM) for up to $96 \mathrm{~h}$. Cell viability decreased markedly by $2.5-5 \mathrm{nM}$ PCX (Fig. 1A). The dose-response experiments showed that $5 \mathrm{nM}$ of PCX is considered to be optimal for the time-course experiments in this study.

PCX-induced cell death exhibits apoptotic characteristics in Saos-2 cells. PCX-induced Saos-2 cell death was characterized by flow cytometry (Fig. 1B). Cell death was increased significantly in a dose-response manner (Fig. 3B), which confirmed that $5 \mathrm{nM}$ of PCX is adequate for the time-course experiments. Annexin V staining was used to identify the type of cell death evoked by PCX (Fig. 1C). PCX significantly increased proportion of apoptotic cells in Saos-2 cells (Fig. 1C).

Caspase-3 activation and decrease of mitochondrial membrane potential are involved in PCX-induced apoptosis in Saos-2 cells. The involvement of caspase-3 activation in PCX-induced apoptosis was examined in Saos-2 cells. Exposure to PCX provoked an increase of caspase-3 cleavage (activation), which reached a post-exposure maximum level
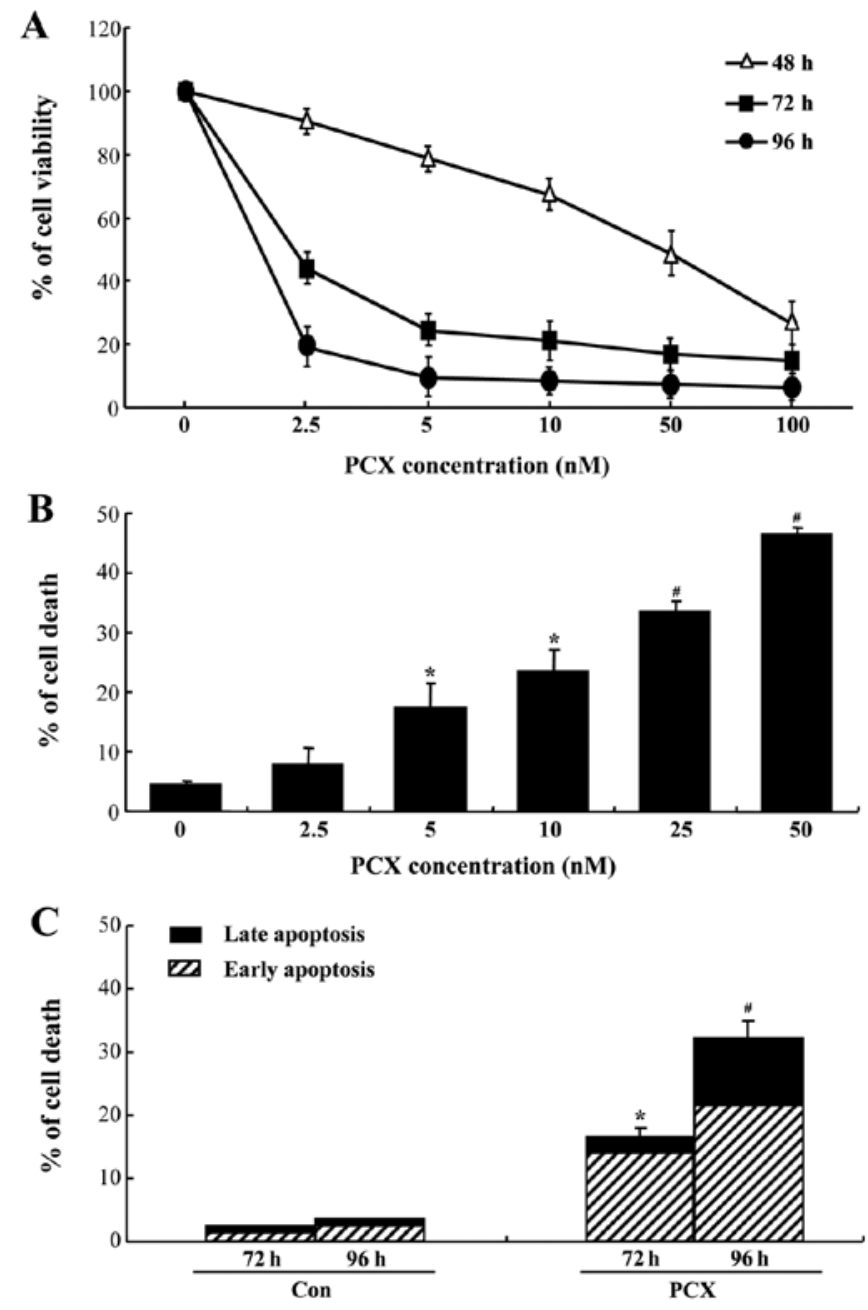

Figure 1. Effects of paclitaxel (PCX) on cell viability and death in Saos-2 osteosarcoma cells. (A) Cell viability shown in cells treated with various concentrations of PCX (2.5-100 $\mathrm{nM})$ for 48, 72 and $96 \mathrm{~h}$ and determined by 3-(4,5-dimethylthiazol-2-yl)-2,5-diphenyltetrazolium bromide (MTT) assay. At least three independent experiments were performed and data shown are the mean \pm SD. (B) Cell death after treatment with increasing concentrations (2.5-50 nM) of PCX for $72 \mathrm{~h}$. Cell death was assessed by flow cytometry. The percentage of cells with a sub-G1 DNA content was taken as a measure of cell death. At least three independent experiments were performed and data shown are the mean \pm SD. ${ }^{*} \mathrm{p}<0.05$ compared to $0 \mathrm{nM}$ control. ${ }^{*} \mathrm{p}<0.001$ compared to $0 \mathrm{nM}$ control. (C) Cell death identified by the Annexin V cell death assay. Con and PCX indicate control and paclitaxel, respectively. At least three independent experiments were performed and data shown are the mean \pm SD. ${ }^{*} \mathrm{p}<0.05$ compared to $72 \mathrm{~h}$ control. ${ }^{*} \mathrm{p}<0.001$ compared to $96 \mathrm{~h}$ control.

with $10 \mathrm{nM}$ concentration at $48 \mathrm{~h}$ (Fig. 2A). Caspase-3 activation was accompanied not only by decrease in XIAP protein level but also by degradation of PARP protein (Fig. 2A). In addition, it has been observed that caspase- 3 activities gradually increase during the duration of PCX treatment (Fig. 2B). In the present study, a decrease of MMP was observed in PCX-treated cells. The rate of mitochondrial depolarization showed a significant increase in PCX-treated cells compared to control (Fig. 2C).

Enhancement of PCX-induced apoptosis by the pretreatment of an autophagy inhibiting molecule. In order to investigate whether autophagic cell death is associated with PCX-induced 
$\mathbf{A}$
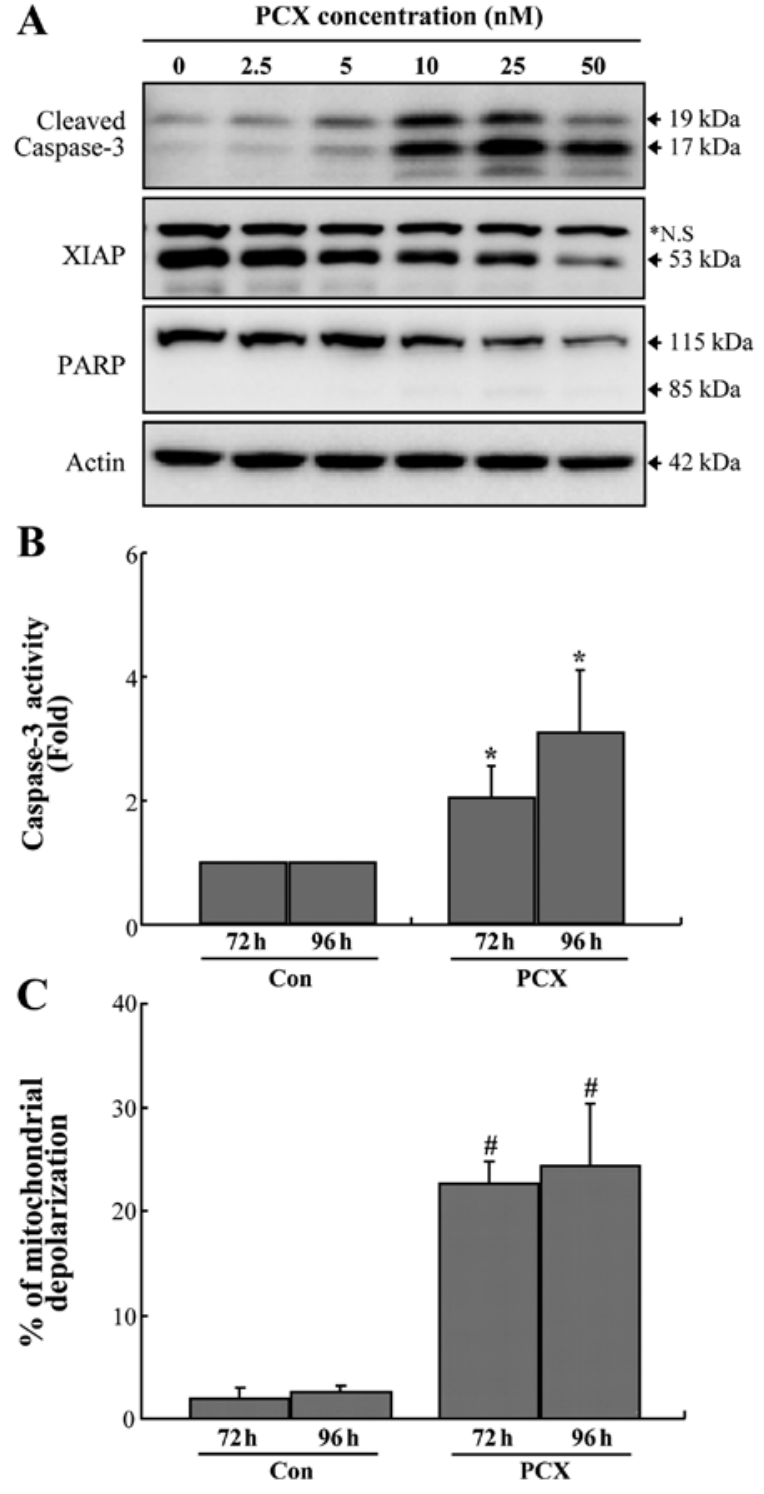

Figure 2. Activation of caspase-3, changes in XIAP and PARP protein levels and depolarization of the mitochondrial membrane potential (MMP, $\Delta \Psi \mathrm{m}$ ) in paclitaxel (PCX)-induced apoptosis in Saos-2 osteosarcoma cells. (A) Western blot analysis of cleaved (active form) caspase-3, XIAP and PARP at $48 \mathrm{~h}$ after increasing concentrations $(2.5-50 \mathrm{nM})$ of PCX treatment. Equal amounts of protein $(30 \mu \mathrm{g})$ were separated by SDS-PAGE and immunoblotted using the indicated antibodies. NS, non-specific binding. Actin expression was used as a loading control. (B) Caspase-3 activity measured spectrofluorometrically using a caspase-3 specific substrate (Ac-DEVD-AMC). Saos-2 cells were treated with $5 \mathrm{nM}$ PCX for 72 and $96 \mathrm{~h}$. At least three independent experiments were performed and data shown are the mean \pm SD. ${ }^{*} \mathrm{p}<0.05$ compared to 72 or $96 \mathrm{~h}$ each control. (C) Graph showing quantification of depolarized MMP. The cells were treated with PCX $(5 \mathrm{nM})$ for 72 and $96 \mathrm{~h}$, stained with Rhodamine 123 and analyzed by flow cytometry. At least three independent experiments were performed and data shown are the mean $\pm \mathrm{SD}$ ${ }^{\#} \mathrm{p}<0.001$ compared to 72 or $96 \mathrm{~h}$ each control.

cell death in Saos-2 cells, a specific inhibitor for autophagy (autophagosome formation; 3-methyladenine, 3-MA) was employed in the experiment of this study. The pretreatment of 3-MA in Soas-2 cells resulted in a significant enhancement of apoptosis provoked by exposure to PCX (Fig. 3A). Although 3 -MA alone also induced cell death $(\leq 10 \%)$, it appeared to be of minimal value considering the capability of 3-MA in increasing cell death induced by PCX. Augmentation of PCX-induced cell death by 3-MA revealed to be involved with caspase-3 activation accompanying by decrease of XIAP proteins (Fig. 3B). In addition, pretreatment with 3-MA or z-VAD-fmk (a pancaspase inhibitor) suppressed the expression of microtubule-associated protein light chain 3 (LC3; specifically LC3-II), an early marker of autophagosome formation, in PCX-treated cells (Fig. 3C). Immunocytochemical staining of LC3 confirmed that autophagic activity increased in the PCX-treated cells, but was suppressed in the presence of 3-MA (Fig. 4). Concomitant with appearance of LC3 proteins, immunoreactive cells for active caspase-3 protein were observed in PCX-treated cells (Fig. 4). However, the pretreatment of 3-MA abolished the LC3 immunoreactivity (Fig. 4) and increased caspase-3-positive cells in PCX-treated cells (Fig. 4).

3-MA enhances cytochrome c release from mitochondria in $P C X$-treated cells. In order to examine whether inhibition of autophagosome formation correlates with the release of mitochondrial apoptotic proteins, the levels of these proteins were monitored in the cytosolic as well as mitochondrial fractions. We showed that 3-MA enhanced PCX-induced release of cytochrome c from the mitochondria (Fig. 5). In contrast, AIF was not released from the mitochondria under these conditions (Fig. 5). Furthermore, the levels of Bcl-2, an antiapoptotic mitochondrial protein, appeared to be decreased after exposure to PCX, but were recovered in the presence of 3-MA (Fig. 5).

\section{Discussion}

During the last few decades, taxanes have been effectively used for the chemotherapeutic treatment of several types of cancers, including breast (27), lung (28), prostate (29) and ovarian (30) cancers. In addition, many in vitro experiments have shown that exposure to taxanes can induce apoptotic cell death in various types of cancer cells (31-33). PCX induces apoptosis in the human osteogenic sarcoma cell lines Saos-2 (34) and U-2 OS (35). Insufficient information is available on taxane-induced apoptosis in OS cells and therefore, taxanes have not been considered for chemotherapeutic regimens for treating OS (26).

Although previous studies have shown PCX-induced apoptosis and related mechanisms in OS cells $(34,35)$, the concentrations of PCX (100-50,000 nM) used for inducing apoptosis were relatively higher than that used in the present study $(5 \mathrm{nM})$. Because high-dose chemotherapy generally causes serious cytotoxic adverse effects in patients, it is important to develop lower-dose chemotherapeutic regimens. The results of the present study confirmed that exposure to low PCX concentrations can induce apoptotic cell death in Saos-2 cells; furthermore, caspase-3 activation, PARP degradation and XIAP downregulation were observed in combination with PCX-induced apoptosis. Both degradation of PARP and decrease in XIAP protein content appeared to be correlated with increased caspase-3 activity. In addition, the potential involvement of mitochondria (intrinsic apoptotic pathway) in PCX-induced apoptosis of OS cells was confirmed by the alteration (depolarization) of the mitochondrial membrane potential as well as the release of cytochrome $\mathrm{c}$ from the 

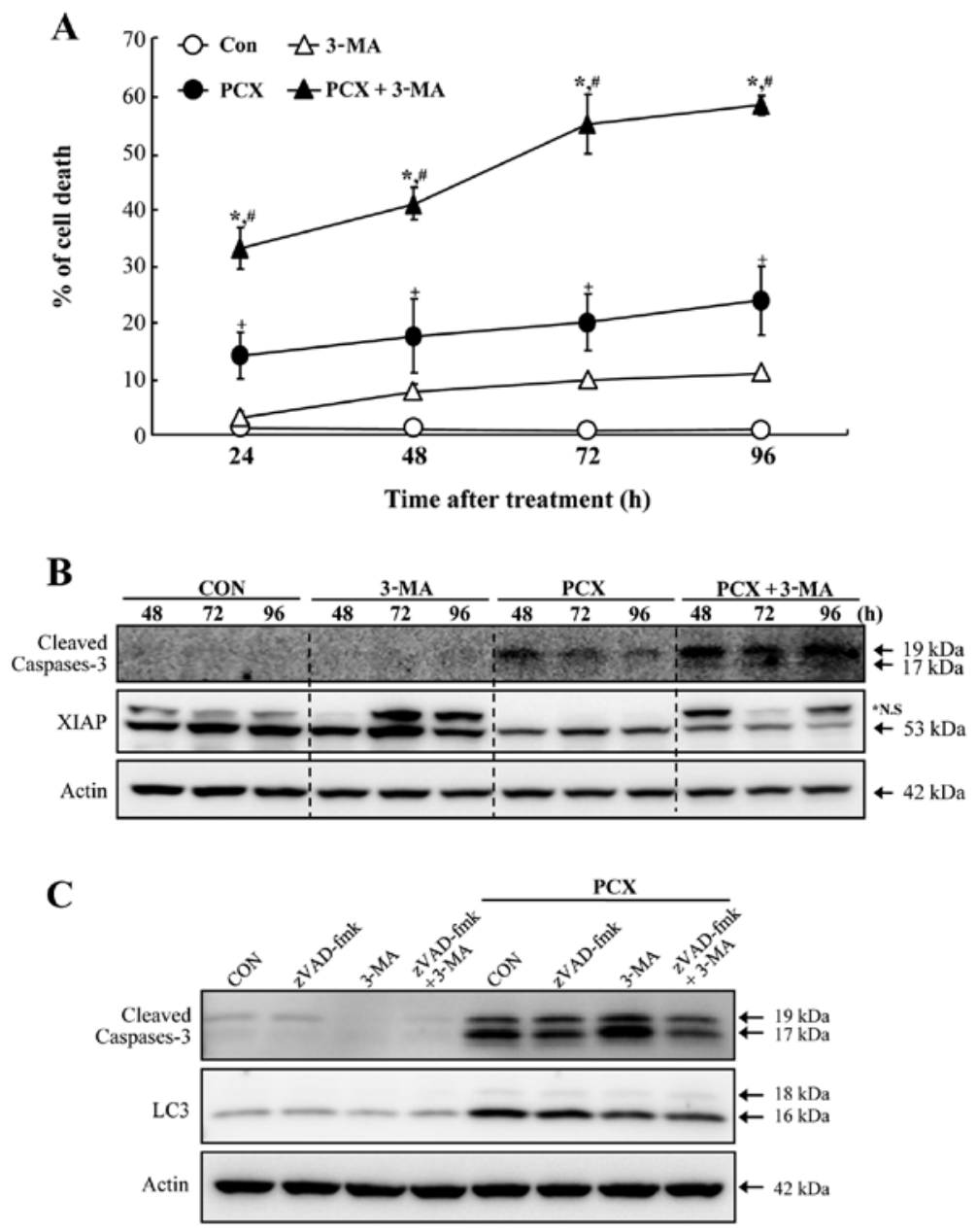

Figure 3. Augmentation of paclitaxel-induced apoptosis in Saos-2 osteosarcoma cells by inhibition of autophagy. (A) Cells were treated with $5 \mathrm{nM}$ PCX up to $96 \mathrm{~h}$ in the absence or presence of a specific autophgy inhibitor, 3-methyladenine (3-MA, $1 \mathrm{mM}$ ). The percentage of cells with a sub-G1 DNA content was taken as a measure of cell death. At least three independent experiments were performed and data shown are the mean \pm SD. ${ }^{+} p<0.05$ compared to control cells. " $\mathrm{p}<0.05$ compared to PCX-treated cells. ${ }^{*} \mathrm{p}<0.001$ compared to control cells. (B) Increase of caspase-3 activation and alterations of XIAP protein levels in Saos-2 osteosarcoma cells after exposure to paclitaxel (PCX) in the absence or presence of 3-methyladenine (3-MA, $1 \mathrm{mM}$ ). Western blot analysis of cleaved (active form) caspase-3 and XIAP at 48, 72 and $96 \mathrm{~h}$ after expose to PCX ( $5 \mathrm{nM})$ treatment. Equal amounts of protein (30 $\mu \mathrm{g})$ were separated by SDS-PAGE and immunoblotted using the indicated antibodies. NS, non-specific binding. Actin expression was used as a loading control. (C) Activation of caspase-3 and expression of LC3 proteins in the absence or presence of the pancaspase inhibitor z-VAD-fmk and/or 3-MA. Western blot analysis of cleaved (active form) caspase- 3 and LC3 at $96 \mathrm{~h}$ after expose to PCX $(5 \mathrm{nM})$ treatment. Equal amounts of protein $(30 \mu \mathrm{g})$ were separated by SDS-PAGE and immunoblotted using the indicated antibodies.
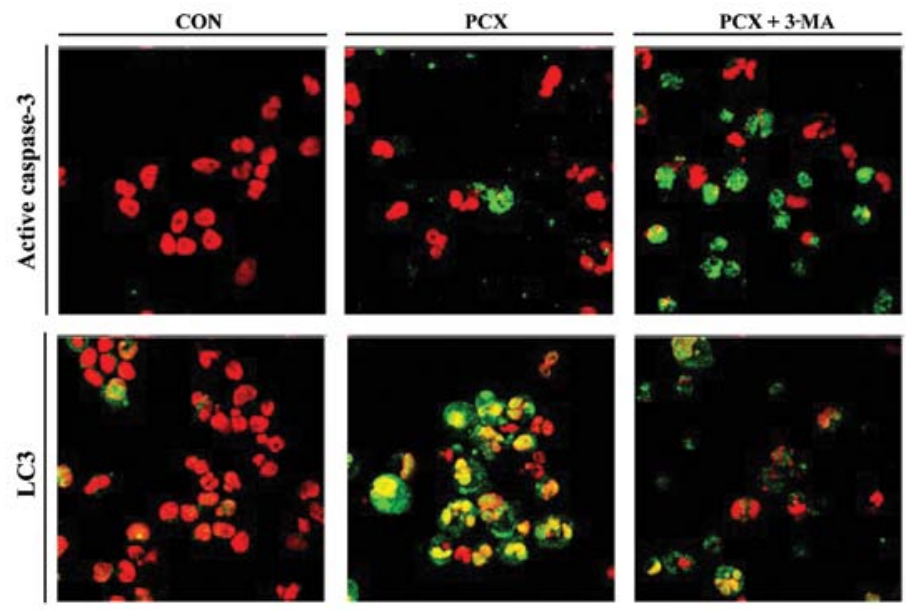

Figure 4. Immunocytochemical localization of active caspase-3 and LC3 proteins in Saos-2 osteosarcoma cells after exposure to paclitaxel (PCX) in the absence or presence of 3-methyladenine (3-MA). The cells were treated with PCX (5 nM) for $96 \mathrm{~h}$ in the absence or in the presence of 3-MA (1 mM), cytospun, fixed and immunostained with the indicated antibodies. Green fluorescence (FITC) indicates immunoreactivity for active caspase-3 and LC-3. For differential nuclear staining, propidium iodide (PI, red) dye was employed. CON, control; PCX, paclitaxel-treated; PCX+3-MA, paclitaxel-treated cells in the presence of 3-MA. Microimages were taken using confocal microscopy. Original magnification, $\mathrm{x} 400$. 


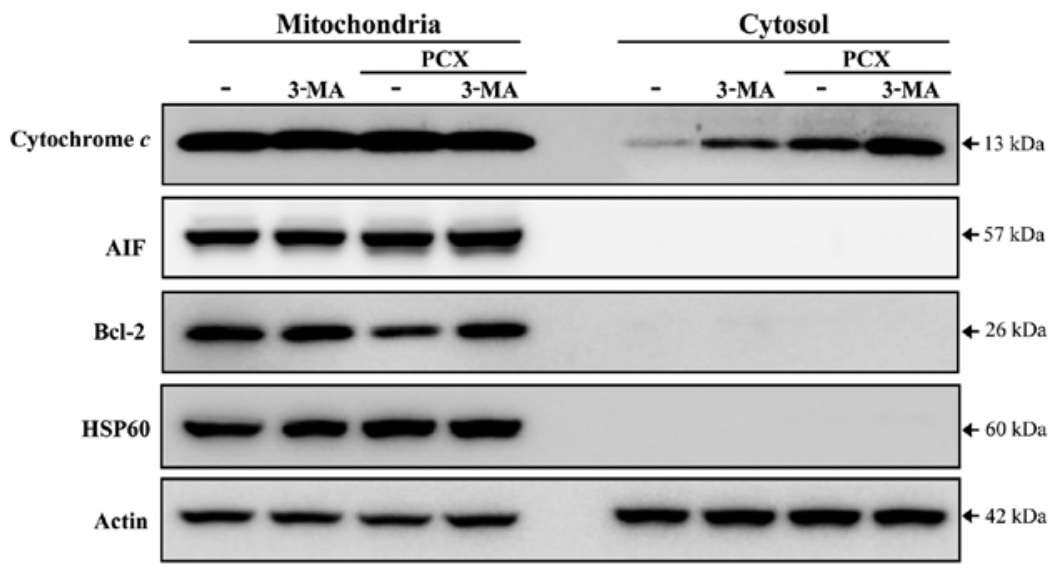

Figure 5. Release of cytochrome c into cytosol from the mitochondria in Saos-2 osteosarcoma cells after exposure to paclitaxel (PCX) in the absence or presence of 3-methyladenine (3-MA). Equal amounts of protein isolated from the mitochondria or the cytosol (30 $\mu \mathrm{g}$ each) were separated by SDS-PAGE and immunoblotted against cytochrome c, AIF, Bcl-2 and HSP60 antibodies. HSP60 was used as an internal loading control for mitochondrial proteins.

mitochondria to the cytoplasm. These results indicate that PCX-induced apoptosis in OS cells is associated with the caspase-dependent pathway, which is consistent with the previous findings for OS cells $(34,35)$.

Similarly, involvement of caspase activation in taxaneinduced apoptosis has been shown in cancer cells originating from the breasts (36), lungs (37), ovaries (38) and prostate (33). In contrast, several studies have shown that PCX-induced apoptosis is not related to caspase activity in some types of cancer cells $(39,40)$. Currently, the precise reason for this inconsistency is not known, but the inconsistency is presumed to be due to cellular differences in tissue origin, status of differentiation, or cell cycle checkpoint/regulatory proteins such as p53 (41). The XIAP protein is an endogenous inhibitor of caspase-3 within cells (11) and has been suggested to be associated with chemoresistance in cancer cells (42). Recently, the potential role of XIAP in chemosensitivity or chemoresistance has been implicated in OS cells (43). However, XIAP downregulation in response to taxane therapy has not been shown in OS cells before this study. Therefore, developing a taxane chemotherapeutic regimen for XIAP downregulation could aid in inducing caspase-dependent apoptosis in OS cells.

Autophagy is currently considered as cell death machinery (programmed cell death type II) that differs from apoptosis (programmed cell death type I) (14). Dysregulation or malfunction of autophagy has been implicated in cancer (44), aging (45), diabetes (46), cardiovascular disease (47), inflammation (48) and neurodegenerative disease (49). Therefore, the selectivity of autophagy and its role in cell death and survival constitute an important issue for understanding the wide spectrum of human health and diseases (50). In the present study, pretreatment with 3-methyladenine (3-MA), a specific inhibitor of autophagy (51), significantly increased PCX-induced apoptotic cell death in Soas-2 cells. The augmentation of PCX-induced apoptosis by 3-MA was accompanied by increase in the cytochrome c release from the mitochondria, caspase-3 activity and XIAP downregulation, which suggests that inhibiting autophagy further stimulates the PCX-induced mitochondrion-related (intrinsic) apoptotic pathway by provoking caspase-3 activation.
Results similar to those obtained in this study have recently been reported for A549 lung cancer cells (52). In these studies, the anti-apoptotic function of autophagy was observed in PCX-induced apoptosis. Collectively, these results indicate the cytoprotective role of autophagy against apoptotic cell death in cancer cells. This cytoprotection does not seem to be restricted to taxane treatment in cancer cells. The cytoprotective function of autophagy has been observed during 5-fluorouracil treatment in colon cancer cells (53), sulforaphane treatment in prostate cancer cells (54), imatinib treatment in glioma cells (55) and suberoylanilide hydroxamic acid treatment in leukemia cells (56). Although the major cellular switch that determines cell destiny (cell death vs. cell survival) by autophagy after exposure to chemotherapeutic drugs remains unclear, the bcl-2 family proteins (bcl-2 and bcl-xL) in the mitochondria are believed to play a pivotal role in regulating autophagy (57).

Microtubule-associated protein light chain 3 (LC3) is now widely used to monitor autophagy (58). LC3 is modified via a ubiquitin-like system (59). LC3 exists in 2 forms: an $18-\mathrm{kDa}$ cytosolic protein (LC3-I) and a processed $16-\mathrm{kDa}$ form (LC3-II) in cells engaged in autophagy. The LC3-II form is mainly localized in autophagosome membranes and therefore, the LC3-II level is a good early marker for autophagosome formation (60). In the present study, immunoreactivity for LC3 markedly increased in Saos-2 cells upon PCX treatment but decreased in the presence of 3-MA. This obviously indicates that PCX treatment increased autophagy. It can be presumed that increased autophagy occurs during the rescue process of cellular structures (i.e.,, organelles) damaged by PCX exposure. Taken together, autophagy observed during PCX-induced apoptosis in Saos-2 OS cells represents the role of cytoprotection in cellular homeostatic processes.

In conclusion, the results of this study revealed that PCX exposure effectively induces OS cell death by apoptosis associated with the mitochondrion-mediated caspase-dependent pathway. PCX can increase autophagic activity and suppressing autophagy enhances PCX-induced apoptosis in OS cells. Therefore, it is suggested that combination treatment involving low-dose PCX therapy and autophagy inhibitor therapy could be an effective and potent strategy for improved chemotherapy for OS in the near future. 


\section{Acknowledgements}

This study was supported by the Dong-A University Research Fund.

\section{References}

1. Dorfman HD and Czerniak B: Bone cancers. Cancer 75: 203-210, 1995.

2. Rytting M, Pearson P, Raymond AK, Ayala A, Murray J, Yasko AW, Johnson M and Jaffe N: Osteosarcoma in preadolescent patients. Clin Orthop Relat Res 373: 39-50, 2000.

3. Longhi A, Errani C, De Paolis M, Mercuri M and Bacci G Primary bone osteosarcoma in the pediatric age: state of the art Cancer Treat Rev 32: 423-436, 2006.

4. Hudson M, Jaffe MR, Jaffe N, Ayala A, Raymond AK, Carrasco H, Wallace S, Murray J and Robertson R: Pediatric osteosarcoma: therapeutic strategies, results and prognostic factors derived from a 10 -year experience. J Clin Oncol 8 : 1988-1997, 1990.

5. Desandes E: Survival from adolescent cancer. Cancer Treat Rev 33: 609-615, 2007.

6. Fellenberg J, Mau H, Nedel S, Ewerbeck V and Debatin KM Drug-induced apoptosis in osteosarcoma cell lines is mediated by caspase activation independent of CD95-receptor/ligand interaction. J Orthop Res 18: 10-17, 2000.

7. Seki K, Yoshikawa H, Shiiki K, Hamada Y, Akamatsu N and Tasaka K: Cisplatin (CDDP) specifically induces apoptosis via sequential activation of caspase- $8,-3$ and -6 in osteosarcoma Cancer Chemother Pharmacol 45: 199-206, 2000.

8. Fu W, Ma L, Chu B, Wang X, Bui MM, Gemmer J, Altiok S and Pledger WJ: The cyclin-dependent kinase inhibitor SCH 727965 (dinacliclib) induces the apoptosis of osteosarcoma cells. Mol Cancer Ther 10: 1018-1027, 2011.

9. Ashkenazi A and Dixit VM: Death receptors: signaling and modulation. Science 281: 1305-1308, 1998.

10. Green DR and Reed JC: Mitochondria and apoptosis. Science 281: 1309-1312, 1998

11. Deveraux QL, Takahashi R, Salvesen GS and Reed JC: X-linked IAP is a direct inhibitor of cell-death proteases. Nature 388 300-304, 1997.

12. Broker LE, Kruyt FA and Giaccone G: Cell death independent of caspases: a review. Clin Cancer Res 11: 3155-3162, 2005.

13. Cande C, Cecconi F, Dessen P and Kroemer G: Apoptosisinducing factor (AIF): key to the conserved caspase-independent pathways of cell death? J Cell Sci 115: 4727-4734, 2002

14. Bursch W: The autophagosomal-lysosomal compartment in programmed cell death. Cell Death Differ 8: 569-581, 2001.

15. Tsujimoto Y and Shimizu S: Another way to die: autophagic programmed cell death. Cell Death Differ 12: 1528-1534, 2005.

16. Grinde B: Autophagy and lysosomal proteolysis in the liver Experientia 41: 1089-1095, 1985.

17. Lum JJ, Bauer DE, Kong M, Harris MH, Li C, Lindsten T and Thompson CB: Growth factor regulation of autophagy and cell survival in the absence of apoptosis. Cell 120: 237-248, 2005

18. Gutierrez MG, Master SS, Singh SB, Taylor GA, Colombo MI and Deretic V: Autophagy is a defense mechanism inhibiting BCG and Mycobacterium tuberculosis survival in infected macrophages. Cell 119: 753-766, 2004.

19. Yu L, Alva A, Su H, Dutt P, Freundt E, Welsh S, Baehrecke EH and Lenardo MJ: Regulation of an ATG7-beclin 1 program of autophagic cell death by caspase- 8 . Science 304: 1500-1502, 2004.

20. Shimizu S, Kanaseki T, Mizushima N, Mizuta T, ArakawaKobayashi S, Thompson CB and Tsujimoto Y: Role of Bcl-2 family proteins in a non-apoptotic programmed cell death dependent on autophagy genes. Nat Cell Biol 6: 1221-1228, 2004.

21. Paludan C, Schmid D, Landthaler M, Vockerodt M, Kube D, Tuschl T and Münz C: Endogenous MHC class II processing of a viral nuclear antigen after autophagy. Science 307: 593-596, 2005.

22. Komatsu M, Waguri S, Chiba T, Murata S, Iwata J, Tanida I, Ueno T, Koike M, Uchiyama Y, Kominami E and Tanaka K: Loss of autophagy in the central nervous system causes neurodegeneration in mice. Nature 441: 880-884, 2006.
23. Mathew R, Karantza-Wadsworth V and White E: Role of autophagy in cancer. Nat Rev Cancer 7: 961-967, 2007.

24. Rowinsky EK, Onetto N, Canetta RM and Arbuck SG: Taxol: the first of the taxanes, an important new class of antitumor agents. Semin Oncol 19: 646-662, 1992

25. Ringel I and Horwitz SB: Effect of alkaline $\mathrm{pH}$ on taxolmicrotubule interactions. J Pharmacol Exp Ther 259: 855-860, 1991.

26. Anninga JK, Gelderblom H, Fiocco M, Kroep JR, Taminiau AH, Hogendoorn PC and Egeler RM: Chemotherapeutic adjuvant treatment for osteosarcoma: where do we stand? Eur J Cancer 47: 2431-2445, 2011

27. Saloustros E, Mavroudis D and Georgoulias V: Paclitaxel and docetaxel in the treatment of breast cancer. Expert Opin Pharmacother 9: 2603-2616, 2008.

28. Chu Q, Vincent M, Logan D, Mackay JA and Evans WK: Lung Cancer Disease Site Group of Cancer Care Ontario's Program in Evidence-based Care. Taxanes as first-line therapy for advanced non-small cell lung cancer: a systematic review and practice guideline. Lung Cancer 50: 355-374, 2005.

29. Obasaju C and Hudes GR: Paclitaxel and docetaxel in prostate cancer. Hematol Oncol Clin North Am 15: 525-545, 2001.

30. Young M and Plosker GL: Paclitaxel: a pharmacoeconomic review of its use in the treatment of ovarian cancer. Pharmacoeconomics 19: 1227-1259, 2001

31. Weigel TL, Lotze MT, Kim PK, Amoscato AA, Luketich JD and Odoux C: Paclitaxel-induced apoptosis in non-small cell lung cancer cell lines is associated with increased caspase-3 activity. J Thorac Cardiovasc Surg 119: 795-803, 2000.

32. Blajeski AL, Kottke TJ and Kaufmann SH: A multistep model for paclitaxel-induced apoptosis in human breast cancer cell lines. Exp Cell Res 270: 277-288, 2001.

33. Kim JY, Chung JY, Lee SG, Kim YJ, Park JE, Yoo KS, Yoo YH, Park YC, Kim BG and Kim JM: Nuclear interaction of Smac/ DIABLO with Survivin at G2/M arrest prompts docetaxelinduced apoptosis in DU145 prostate cancer cells. Biochem Biophys Res Commun 350: 949-954, 2006.

34. Pucci B, Bellincampi L, Tafani M, Masciullo V, Melino G and Giordano A: Paclitaxel induces apoptosis in Saos-2 cells with CD95L upregulation and Bcl-2 phosphorylation. Exp Cell Res 252: 134-143, 1999.

35. Lu KH, Lue KH, Chou MC and Chung JG: Paclitaxel induces apoptosis via caspase-3 activation in human osteogenic sarcoma cells (U-2 OS). J Orthop Res 23: 988-994, 2005.

36. Kovar J, Ehrlichov M, Smejkalov B, Zanardi I, Ojima I and Gut I: Comparison of cell death-inducing effect of novel taxane SB-T-1216 and paclitaxel in breast cancer cells. Anticancer Res 29: 2951-2960, 2009.

37. Osaki S, Nakanishi Y, Takayama K, Pei XH, Ueno H and Hara N: Transfer of IkappaBalpha gene increase the sensitivity of paclitaxel mediated with caspase 3 activation in human lung cancer cell. J Exp Clin Cancer Res 22: 69-75, 2003.

38. Ueno NT, Bartholomeusz C, Herrmann JL, Estrov Z, Shao R andreeff M, Price J, Paul RW, Anklesaria P, Yu D and Hung MC: E1A-mediated paclitaxel sensitization in HER-2/neu-overexpressing ovarian cancer SKOV3.ip1 through apoptosis involving the caspase-3 pathway. Clin Cancer Res 6: 250-259, 2000

39. Huisman C, Ferreira CG, Broker LE, Rodriguez JA, Smit EF, Postmus PE, Kruyt FA and Giaccone G: Paclitaxel triggers cell death primarily via caspase-independent routes in the non-small cell lung cancer cell line NCI-H460. Clin Cancer Res 8: 596-606, 2002.

40. Ofir R, Seidman R, Rabinski T, Krup M, Yavelsky V, Weinstein Y and Wolfson M: Taxol-induced apoptosis in human SKOV3 ovarian and MCF7 breast carcinoma cells is caspase-3 and caspase-9 independent. Cell Death Differ 9: 636-642, 2002.

41. Vikhanskaya F, Vignati S, Beccaglia P, Ottoboni C, Russo P, D'Incalci $M$ and Broggini M: Inactivation of p53 in a human ovarian cancer cell line increases the sensitivity to paclitaxel by inducing G2/M arrest and apoptosis. Exp Cell Res 241: 96-101, 1998.

42. Sasaki H, Sheng Y, Kotsuji F and Tsang BK: Down-regulation of X-linked inhibitor of apoptosis protein induces apoptosis in chemoresistant human ovarian cancer cells. Cancer Res 60: 5659-5666, 2000.

43. Fellenberg J, Kunz P, Suhr H and Depeweg D: Overexpression of inosine 5'-monophosphate dehydrogenase type II mediates chemoresistance to human osteosarcoma cells. PLoS One 5: e12179, 2010 
44. Kimmelman AC: The dynamic nature of autophagy in cancer. Genes Dev 25: 1999-2010, 2011.

45. Rubinsztein DC, Mariño G and Kroemer G: Autophagy and aging. Cell 146: 682-695, 2011.

46. Jung HS and Lee MS: Role of autophagy in diabetes and mitochondria. Ann NY Acad Sci 1201: 79-83, 2010.

47. Nemchenko A, Chiong M, Turer A, Lavandero S and Hill JA: Autophagy as a therapeutic target in cardiovascular disease. J Mol Cell Cardiol 51: 584-593, 2011.

48. Levine B, Mizushima N and Virgin HW: Autophagy in immunity and inflammation. Nature 469: 323-335, 2011.

49. Alirezaei M, Kemball CC and Whitton JL: Autophagy, inflammation and neurodegenerative disease. Eur J Neurosci 33 197-204, 2011.

50. Yu L, Strandberg L and Lenardo MJ: The selectivity of autophagy and its role in cell death and survival. Autophagy 4: 567-573, 2008.

51. Seglen PO and Gordon PB: 3-Methyladenine: specific inhibitor of autophagic/lysosomal protein degradation in isolated rat hepatocytes. Proc Natl Acad Sci USA 79: 1889-1892, 1982

52. Xi G, Hu X, Wu B, Jiang H, Young CY, Pang Y and Yuan H: Autophagy inhibition promotes paclitaxel-induced apoptosis in cancer cells. Cancer Lett 307: 141-148, 2011.

53. Li J, Hou N, Faried A, Tsutsumi S and Kuwano H: Inhibition of autophagy augments 5-fluorouracil chemotherapy in human colon cancer in vitro and in vivo model. Eur J Cancer 46: 1900-1909, 2010.
54. Herman-Antosiewicz A, Johnson DE and Singh SV: Sulforaphane causes autophagy to inhibit release of cytochrome $\mathrm{C}$ and apoptosis in human prostate cancer cells. Cancer Res 66: 5828-5835, 2006.

55. Shingu T, Fujiwara K, Bugler O, Akiyama Y, Moritake K, Shinojima N, Tamada Y, Yokoyama T and Kondo S: Inhibition of autophagy at a late stage enhances imatinib-induced cytotoxicity in human malignant glioma cells. Int J Cancer 124: 1060-1071, 2009.

56. Carew JS, Nawrocki ST, Kahue CN, Zhang H, Yang C, Chung L, Houghton JA, Huang P, Giles FJ and Cleveland JL: Targeting autophagy augments the anticancer activity of the histone deacetylase inhibitor SAHA to overcome Bcr-Abl-mediated drug resistance. Blood 110: 313-322, 2007.

57. Levine B, Sinha S and Kroemer G: Bcl-2 family members: dual regulators of apoptosis and autophagy. Autophagy 4: 600-606, 2008.

58. Tanida I, Minematsu-Ikeguchi N, Ueno T and Kominami E: Lysosomal turnover, but not a cellular level, of endogenous LC3 is a marker for autophagy. Autophagy 1: 84-91, 2005.

59. Ohsumi Y: Molecular dissection of autophagy: two ubiquitin-like systems. Nat Rev Mol Cell Biol 2: 211-216, 2001.

60. Kabeya Y, Mizushima N, Ueno T, Yamamoto A, Kirisako T, Noda T, Kominami E, Ohsumi Y and Yoshimori T: LC3, a mammalian homologue of yeast Apg8p, is localized in autophagosome membranes after processing. EMBO J 19: 5720-5728, 2000 . 